\title{
DESENVOLVIMENTO RURAL EM ESCALA \\ MICRORREGIONAL: UMA ANÁLISE ENTRE \\ MICRORREGIÕES FUMICULTORAS E NÃO FUMICULTORAS \\ NO RIO GRANDE DO SUL NA PRIMEIRA DÉCADA DO \\ SÉCULO $21^{1}$
}

\author{
RURAL DEVELOPMENT IN MICRO-REGIONAL SCALE: A \\ MICRO ANALYSIS OF NON-TOBACCO GROWING AND \\ TOBACCO GROWING IN RIO GRANDE DO SUL IN THE \\ FIRST DECADE OF THE 21ST CENTURY
}

\author{
Marcelo Antonio Conterato \\ Universidade Federal do Rio Grande do Sul - RS - Brasil
}

\begin{abstract}
Resumo: O objetivo deste trabalho é apresentar e analisar alguns resultados em termos de dinâmicas regionais de desenvolvimento rural para o Rio Grande do Sul na primeira década do século 21, privilegiando a comparação entre regiões fumicultoras e não fumicultoras. Isso será feito através da construção de um Índice de Desenvolvimento Rural (IDR) para as 35 microrregiões do estado do Rio Grande do Sul definidas pelo Instituto Brasileiro de Geografia e Estatística (IBGE). Para construção do IDR foram considerados 36 indicadores distribuídos em 5 dimensões (Social, Demográfica, Político-Institucional, Econômica e Ambiental). A hipótese inicial levantada foi confirmada, visto que a área cultivada com tabaco no Rio Grande do Sul, considerando-se os anos de 2000 e 2008, teria avançado principalmente nas regiões menos dinâmicas, de menor IDR. Foi possível atestar ainda que o avanço do cultivo do tabaco no período considerado também se deu nas regiões tradicionalmente fumicultoras, que se caracterizam por apresentar baixo IDR, embora tenha avançado também em algumas regiões não tradicionalmente fumicultoras, estas de IDR ainda mais baixo. A metodologia adotada não permitiu associar diretamente o avanço da fumicultura com pioras ou melhoras nos indicadores de desenvolvimento rural ou análises em termos de (in)sustentabilidade, já que cada variável é tomada em apenas um ponto no tempo. Ainda assim foi possível constatar a validade da proposta metodológica para análises comparativas no espaço (caso deste trabalho) e no tempo (permitindo comparações e variações ao longo do tempo).
\end{abstract}

Palavras-chave: Desenvolvimento rural. Desigualdades regionais. Tabaco.

ABSTRACT: The objective of this paper is to present and analyze some results in terms of regional dynamics of rural development for the Rio Grande do Sul in the first decade of the 21st century, emphasizing the comparison between non-tobacco growing and tobacco growing regions. This will be done through the construction of a Rural Development Index (RDI) for 35 micro-regions of the state of Rio Grande do Sul defined by the Brazilian Institute of Geography and Statistics (IBGE). For construction of the IDR were considered 36 indicators divided into five dimensions (social, demographic, political-institutional, economic and environmental). The initial hypothesis was confirmed raised, since the area under tobacco in Rio Grande do Sul, considering the years 2000 and 2008, would have advanced mainly in the less dynamic, less IDR. It can also attest that the development of tobacco cultivation in the period considered is also given in the tobacco growing regions traditionally characterized by low IDR presented, although well advanced in some areas not traditionally tobacco growing, these IDR even lower. The methodology adopted is not possible to

\footnotetext{
${ }^{1}$ Este trabalho contou com o apoio financeiro da Fundação de Amparo à Pesquisa do Estado do Rio Grande do Sul (FAPERGS) na modalidade Auxílio Recém-Doutor (ARD), a quem o autor registra seus agradecimentos.
} 
correlate directly with the advancement of tobacco growing worse or better in the indicators of rural development or analysis in terms of (un) sustainability, since each variable is taken at only one point in time. Still, we determined the validity of the methodology for comparative analysis in space (if this work) and time (allowing comparisons and changes over time)

Keywords: Rural development. Regional inequalities. Tobacco.

\section{Introdução}

De uma maneira geral, o reconhecimento das condições desiguais em que o desenvolvimento rural encontra respaldo empírico insere-se num quadro teóricometodológico que tende a reconhecer a diversidade e a heterogeneidade dos formatos tecnológicos, econômicos e institucionais enquanto aspectos da ruralidade contemporânea. A ênfase cada vez mais centra-se nas relações entre as formas de agricultura, que no Rio Grande do Sul é majoritariamente de base familiar $^{2}$, e sua relação com os processos de desenvolvimento regional. As dinâmicas de desenvolvimento rural de inúmeras regiões no Brasil e no Rio Grande do Sul tendem a se vincular estreitamente com os estilos regionais assumidos pela agricultura, especialmente a de base familiar. Nesses termos, pode-se considerar que há uma forte associação entre as condições sociais e econômicas de reprodução desta categoria social e as configurações regionais do desenvolvimento rural, indicando que regiões mais desenvolvidas tendem a apresentar uma agricultura familiar mais pujante, ao passo que em regiões menos desenvolvidas a agricultura familiar tende a ser mais vulnerável social e economicamente.

O objetivo deste trabalho é investigar a intensidade e o formato das desigualdades regionais de desenvolvimento rural no Rio Grande do Sul, tomando como referência empírica as 35 microrregiões homogêneas delimitadas pelo Instituto Brasileiro de Geografia e Estatística (IBGE) (Figura 1). Para tanto nos valemos de metodologias já existentes e detalhadas nas próximas seções para a construção de um Índice de Desenvolvimento Rural (IDR) capaz de representar a intensidade e o formato das desigualdades regionais. A representação da intensidade será feita através dos índices e subíndices enquanto o formato será representado pelas dimensões.

A primeira prerrogativa que motivou a realização deste estudo partiu da persistência das já históricas desigualdades regionais de desenvolvimento existentes no Rio Grande do Sul. A segunda prerrogativa decorreu da constatação do contínuo avanço da área cultivada com tabaco no período recente no Rio Grande do Sul e da constatação prévia de que as regiões fumicultoras apresentam indicadores de desenvolvimento abaixo da média estadual. Isso seria também válido em relação ao desenvolvimento rural?

A Organização das Nações Unidas para Agricultura e Alimentação (FAO) prevê que nos países em desenvolvimento a tendência continuará sendo de

\footnotetext{
${ }^{2}$ Basta observar os dados do Censo Agropecuário 2006 que demonstram a representatividade do universo agrícola familiar (segundo Lei 11.326/2006 - Lei da Agricultura Familiar). No Brasil, essa categoria social representa $84,4 \%$ do total de estabelecimentos agropecuários, enquanto no Rio Grande do Sul este percentual alcança $85,7 \%$.
} 
crescimento da produção de tabaco, com gradativa redução da área plantada. Essa ampliação da produção decorre principalmente de mudanças nas estratégias das multinacionais fumageiras que vislumbraram nos países pobres ou em desenvolvimento possibilidades de ampliação dos seus negócios; do crescimento da demanda de consumo mundial, concentrada principalmente nos países em desenvolvimento; dos baixos custos da mão de obra aproveitando-se de ampla disseminação da categoria social agricultor familiar; e da lucratividade que o fumo proporciona em comparação a outros cultivos, ainda que seja alvo de controvérsia.

O Brasil é um dos principais produtores mundiais de tabaco e os principais estados produtores estão na Região Sul, onde milhares de agricultores familiares possuem na produção de tabaco a principal, senão a única, fonte de rendimento. Somente os estados da região Sul representavam mais de $95 \%$ da produção brasileira de tabaco que, em 2005, totalizou praticamente 900 mil toneladas, cabendo ao Rio Grande do Sul praticamente $50 \%$ da área e $52 \%$ do volume ${ }^{3}$. Historicamente, no Rio Grande do Sul a fumicultura se concentra nas regiões Centro Ocidental, Metropolitana, Sudeste e Noroeste. Recentemente tem se observado uma migração do cultivo do tabaco para algumas regiões do Estado onde o mesmo não era expressivo.

De acordo com Bonato (2009), quase 200 mil famílias estão envolvidas na produção do tabaco, a maioria de agricultores familiares, representando quase um quarto dos agricultores familiares da região Sul. Com os avanços recentes em área plantada aliada às melhorias genéticas e a toda guarida oferecida pelas empresas fumageiras aos agricultores tornaram o Brasil, de forma muito rápida, o principal país exportador do produto. Nesses termos, este trabalho pretende contribuir com a perspectiva teórica que volta seu foco para a dimensão espacial do desenvolvimento, demonstrando que a diversidade se expressa nas mais diversas unidades territoriais e nas mais diversas faces ou dimensões (VEIGA, 2000; 2002). Embora existam traços comuns da ruralidade, o meio rural caracteriza-se pela sua imensa diversidade e estabelecer tipologias capazes de captar esta diversidade é uma das importantes missões das pesquisas contemporâneas voltadas para a dimensão espacial do desenvolvimento (ABRAMOVAY, 2003).

O presente artigo está estruturado em cinco seções, contempladas introdução e considerações finais. Na seção 2 procura-se apresentar a perspectiva teórica sobre desenvolvimento rural na qual nos apoiamos para construir este trabalho. Na seção 3 são contemplados os critérios metodológicos adotados para a construção do IDR, apresentando as variáveis, as dimensões e os demais procedimentos metodológicos. A quarta seção é destinada à caracterização dos indicadores de desenvolvimento rural, a suas respectivas dimensões, à apresentação do índice sintético (IDR) e a suas representações gráficas bem como territoriais. Ao final são indicadas algumas considerações finais quanto à proposta metodológica e a possíveis implicações do trabalho em termos de políticas públicas para as regiões produtoras de tabaco.

\footnotetext{
3 Informações adicionais a respeito da cadeia produtiva do fumo podem ser obtidas em documentos produzidos pelo Departamento de Estudos Socioeconômicos Rurais (DESER), disponíveis em www.deser.org.br.
} 


\section{Desenvolvimento Rural: fazendo escolhas}

O debate sobre desenvolvimento rural ${ }^{4}$, desenvolvido particularmente a partir de meados da década de 1990, não se resume ao que está indicado neste trabalho, quer seja o debate nacional ou internacional. Das diversas definições mais recentes sobre desenvolvimento rural (PLOEG, ET AL, 2000; VEIGA, 2002; ABRAMOVAY, 2003; KAGEYAMA, 2006; SCHNEIDER, 2006) pode-se extrair a ideia de que o mesmo deve ser o resultado da combinação de aspectos econômicos, sociais e institucionais, resultando daí fortalecimento da possibilidade de diversificação das fontes de rendimento das famílias, quer seja via atividades agropecuárias, quer seja através de outras formas de mercantilização do espaço agrário. Outro avanço importante foi o reconhecimento de que o desenvolvimento rural tem de específico o fato de referir-se a uma base territoria/na qual interagem diversos agentes e setores produtivos, o que significa reconhecer também a multissetorialidade do desenvolvimento rural. $\mathrm{O}$ fato de as áreas rurais desempenharem diferentes funções, contribuindo cada qual a sua maneira para o desenvolvimento, define tal espaço como multifuncional.

Pode-se extrair das abordagens apresentadas um conjunto de elementos que favorecem (ou compõem) o desenvolvimento rural, sistematizados em Kageyama (2006): 1) a integração mercantil com cidades da própria região, uma vez que o dinamismo econômico das cidades de médio porte, a partir de atividades "terciárias", favorece o desenvolvimento das comunidades rurais "adjacentes"; 2) regiões de agricultura familiar consolidada, combinada com processo de urbanização e industrialização endógeno e descentralizado possibilitam um mercado local de consumo de produtos diversificados e fornecimento de matériasprimas e mão de obra rural para a indústria local; 3) a pluriatividade das famílias rurais, que permite a retenção de população rural e redução do êxodo; 4) a diversidade das fontes de renda, que permite maior autonomia (menor dependência da atividade agrícola exclusiva) e menor instabilidade da renda; 5) os programas de geração de emprego e de melhoria da qualidade de vida, que permitem reduzir as migrações, e a luta contra o isolamento (OCDE, 1996); 6) a existência de recursos territoriais que permitam produzir para mercados específicos (vinhos, turismo, etc.), possibilitando a internalização de externalidades positivas (MOLLARD, 2003).

\footnotetext{
${ }^{4} \mathrm{O}$ acumulado teórico sobre desenvolvimento rural é infinitamente maior do que o apresentado nesta seção. Sabedor dessa limitação, fizemos a escolha de desenvolver apenas, mesmo que sucintamente, apenas a escolha teórica mais adequada aos objetivos deste trabalho. Para encontrar numa mesma obra um conjunto de proposições teóricas e metodológicas acerca do rural, recomendamos a leitura de Conterato, Radomsky e Schneider (2014). Representando uma perspectiva mais econômica e, por conseguinte, mais disciplinar reconhecemos a importância e a influência que o livro organizado por Buainain, Alves, Silveira e Navarro (2014) representa nos estudos rurais e agrícolas no Brasil.
} 
Qualquer análise do desenvolvimento rural ou de seu potencial em níveis locais e regionais deveria levar em conta esses elementos. Regiões com redes urbanas bem distribuídas, com recursos territoriais adequados, mercados locais que favoreçam a pluriatividade, podem apresentar um grau mais elevado de desenvolvimento rural, em contraste com áreas isoladas, sem privilégios naturais e sem instituições locais adequadas. Não nos propomos a este nível de detalhamento, mas acredita-se que o IDR proposto e a comparação entre as regiões deixarão mais evidente que as desigualdades regionais são construções históricas e refletem antes de tudo as desiguais condições em que o rural e a agricultura se vinculam com as redes urbanas, definindo assim distintas funções desempenhadas pelo rural.

\section{0 Índice de Desenvolvimento Rural (IDR)}

A proposta metodológica do IDR baseia-se em conjunto de estudos recentes (WAQUIL, et al. 2007; SEPÚLVEDA, 2005; KAGEYAMA, 2006, 2008; CONTERATO, 2008; CONTERATO et al, 2007) que tiveram por objetivo analisar as dinâmicas de desenvolvimento rural e territorial numa perspectiva multidimensional. Tal como naqueles trabalhos, neste buscou-se priorizar elementos rurais na construção do IDR. Tal ênfase recobre-se de importância na medida em que se busca verificar se também em relação ao desenvolvimento rural as regiões fumicultoras apresentam indicadores mais precários na comparação com regiões não fumicultoras. Para que a comparação seja factível, o esforço metodológico resulta na construção de um indicador sintético de desenvolvimento, um Índice de Desenvolvimento Rural (IDR), para cada uma das 35 microrregiões.

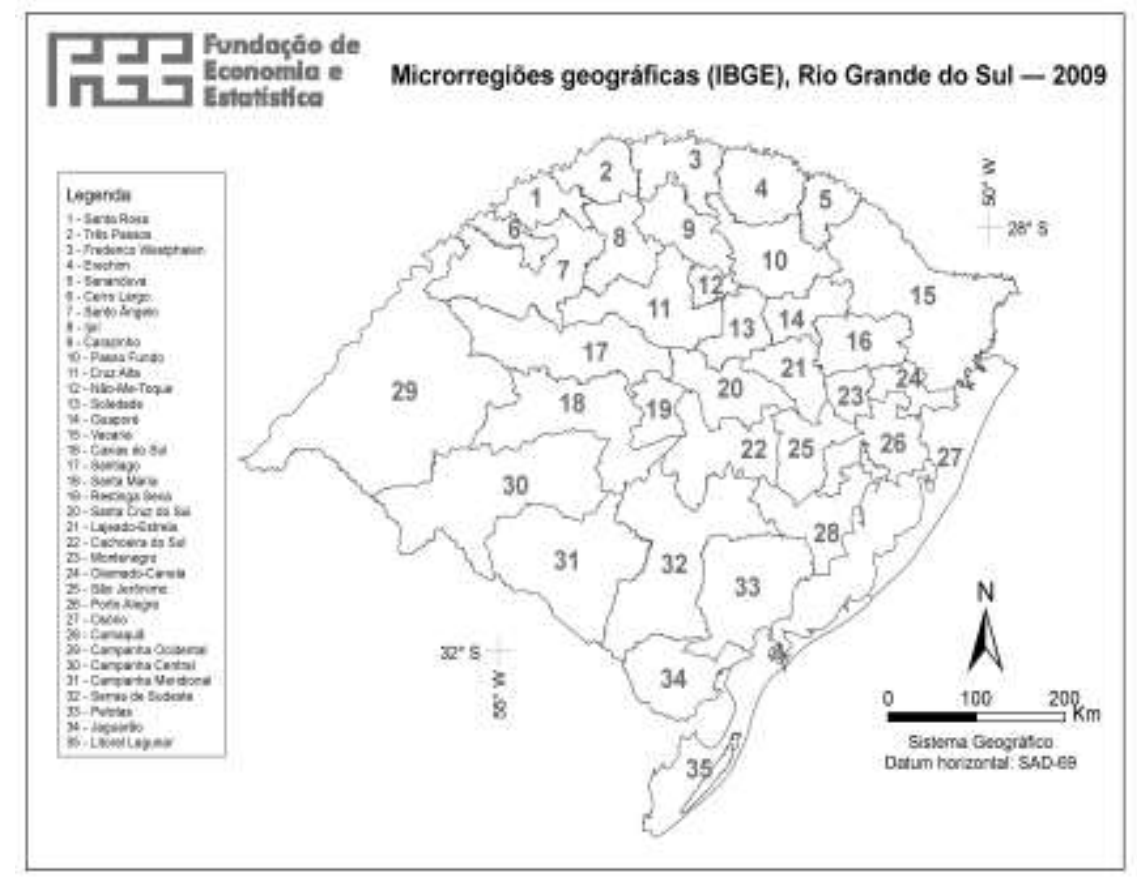

Figura 1. Microrregiões do Rio Grande do Sul, 2009

Fonte: FEE, 2010 
Cada uma das cinco dimensões é alimentada por um conjunto de indicadores que resultarão em subíndices, por dimensão. Esses subíndices, em seu conjunto, compõem o IDR para cada microrregião que por sua vez formarão o IDR médio. Quanto mais próximo de 1 melhor é a condição de desenvolvimento rural daquela microrregião e do seu agregado. Quanto mais próximo de 0 pior é a sua condição. São 36 indicadores assim distribuídos entre as 5 dimensões: 8 na dimensão social, 6 na demográfica, 5 na político-institucional, 12 na econômica e 5 na ambiental. Os indicadores e as dimensões possuem o mesmo peso na formação do IDR. A única distinção foi determinar o sentido da contribuição de cada indicador, se positiva (+) ou negativa (-) ao desenvolvimento.

A definição dos sinais e pesos das variáveis é outra fase crucial da construção do IDR. Conforme retrata o Quadro 1, as variáveis observadas possuem diferentes unidades de medida, o que requer uma uniformização, transformando as variáveis em índices, permitindo assim a agregação das mesmas nas respectivas dimensões. O procedimento adotado ajusta os valores observados das variáveis a escalas cujo valor mínimo é 0 (zero) e valor máximo é igual a 1 (um), criando condições para a agregação nas respectivas dimensões, a estimação do IDR e a sua representação gráfica. 
Desenvolvimento Rural em escala microrregional: uma análise entre microrregiões...

\begin{tabular}{|c|c|c|c|}
\hline Dimensões & Indicador e relação com o desenvolvimento & Unidade Medida & Fonte \\
\hline \multirow{8}{*}{ Social } & \multirow{4}{*}{$\begin{array}{l}\text { IDESE Saúde (2006) (+) } \\
\text { IDESE Educação (2006) (+) } \\
\text { Tx analfabetismo pessoas } 10 \text { anos ou mais rural (2000) (-) } \\
\text { Pessoas entre } 18 \text { e } 29 \text { anos freqüentando curso superior } \\
(2000)(+)\end{array}$} & Índice & FEEDADOS \\
\hline & & Índice & FEEDADOS \\
\hline & & $\%$ & Censo Demográfico IBGE \\
\hline & & $\%$ & Censo Demográfico IBGE \\
\hline & Domicílios rurais linha telefônica (2000) (+) & $\%$ & Censo Demográfico IBGE \\
\hline & Acesso iluminação elétrica $(2000)(+)$ & $\%$ & Censo Demográfico IBGE \\
\hline & Abastecimento água - rede geral - rural $(2000)(+)$ & $\%$ & \\
\hline & Esgoto sanitário - fossa séptica - rural (2000) & $\%$ & Censo Demográfico IBGE \\
\hline \multirow{6}{*}{ Demográfica } & \multirow{6}{*}{$\begin{array}{l}\text { Taxa de Urbanização (2008) (+) } \\
\text { Densidade Demográfica (2008) (+) } \\
\text { População Rural entre } 15 \text { e } 24 \text { anos (2000) (pessoas } 10 \\
\text { anos ou mais) (+) } \\
\text { Razão População Masculina Rural / Feminina Rural (2000) } \\
(+) \\
\text { População rural mais } 60 \text { anos (2000) (+) } \\
\text { Moradores por dormitório rural (2000) (mais de } 2 \\
\text { moradores) (-) }\end{array}$} & $\%$ & Censo Demográfico IBGE \\
\hline & & $\mathrm{hab} / \mathrm{km} 2$ & Censo Demográfico IBGE \\
\hline & & $\%$ & Censo Demográfico IBGE \\
\hline & & Razão & Censo Demográfico IBGE \\
\hline & & $\%$ & Censo Demográfico IBGE \\
\hline & & \% domicílios & Censo Demográfico IBGE \\
\hline \multirow{5}{*}{$\begin{array}{l}\text { Político- } \\
\text { Institucional }\end{array}$} & $\begin{array}{l}\text { Pessoas com mais de } 50 \% \text { da renda formada por } \\
\text { transferências governamentais }(2000)(-)\end{array}$ & $\%$ & Atlas Desen. Humano \\
\hline & $\begin{array}{l}\text { Transferências Intergovernamentais da União na } \\
\text { composição da receita orçamentária municipal(2000) (-) }\end{array}$ & $\begin{array}{l}\text { \% da Receita } \\
\text { Orçamentária } \\
\text { municipal }\end{array}$ & Ministério Fazenda \\
\hline & Eleitores Analfabetos (2008) (-) & $\%$ & $\begin{array}{l}\text { Tribunal Superior } \\
\text { Eleitoral }\end{array}$ \\
\hline & Empreendimentos em Economia Solidária (2007) (+) & $\mathrm{n}$. & Ministério Trabalho \\
\hline & $\begin{array}{l}\text { Estabelecimentos declaram utilizar serviços assistência } \\
\text { técnica }(1996)(+)\end{array}$ & $\%$ & $\begin{array}{l}\text { Censo Agropecuário - } \\
\text { IBGE }\end{array}$ \\
\hline \multirow{11}{*}{ Econômica } & IDESE Renda (2006) (+) & $\begin{array}{l}\text { índice } \\
\text { Índice (soma }\end{array}$ & FEEDADOS \\
\hline & Grau Concentração Formação PIB (2006) (-) & $\begin{array}{l}\text { quadrados } \\
\text { participações) }\end{array}$ & FEEDADOS \\
\hline & PIB per capita (2006) (+) & $\mathrm{R} \$$ per capita & FEEDADOS \\
\hline & VBP pessoa ocupada agricultura $(1995 / 96)(+)$ & $\mathrm{R} \$$ pessoa ocupada & $\begin{array}{l}\text { Censo Agropecuário - } \\
\text { IBGE }\end{array}$ \\
\hline & VBP por estabelecimento agrop. (1995/96) (+) & $\begin{array}{l}\mathrm{R} \$ \\
\text { estabelecimento }\end{array}$ & $\begin{array}{l}\text { Censo Agropecuário - } \\
\text { IBGE }\end{array}$ \\
\hline & Pessoas ocupadas por estabelecimento agrop. (1996) (+) & Pessoas & $\begin{array}{l}\text { Censo Agropecuário - } \\
\text { IBGE }\end{array}$ \\
\hline & $\begin{array}{l}\text { Concentração produção agrop. (participação principal } \\
\text { produto no VBP total) (1996) (-) }\end{array}$ & $\%$ & $\begin{array}{l}\text { Censo Agropecuário - } \\
\text { IBGE }\end{array}$ \\
\hline & Domicílios rurais com automóvel particular (2000) (+) & $\%$ & $\begin{array}{l}\text { Censo Demográfico - } \\
\text { IBGE }\end{array}$ \\
\hline & $\begin{array}{l}\text { Domicílios rurais que percebem até } 1 \text { salário mínimo } \\
(2000)(-)\end{array}$ & $\%$ & $\begin{array}{l}\text { Censo Demográfico - } \\
\text { IBGE }\end{array}$ \\
\hline & $\begin{array}{l}\text { Estabelecimentos agrop. Produtor declarou ter rendimento } \\
\text { fora estabelecimento }(2006)(+)\end{array}$ & $\%$ & $\begin{array}{l}\text { Censo Agropecuário } \\
2006\end{array}$ \\
\hline & $\begin{array}{l}\text { Estabelecimentos agrop. Produtor declarou ter rendimento } \\
\text { não agrícola fora estabelecimento }(2006)(+)\end{array}$ & $\%$ & $\begin{array}{l}\text { Censo Agropecuário } \\
2006\end{array}$ \\
\hline \multirow{5}{*}{ Ambiental } & Estabelecimentos práticas de conservação (1996) (+) & $\begin{array}{l}\% / \text { total } \\
\text { estabelecimentos }\end{array}$ & $\begin{array}{l}\text { Censo Agropecuário - } \\
\text { IBGE }\end{array}$ \\
\hline & Matas (naturais e plantadas) (2006) (+) & $\begin{array}{l}\text { \% sobre área } \\
\text { agrícola total }\end{array}$ & $\begin{array}{l}\text { Censo Agropecuário - } \\
\text { IBGE }\end{array}$ \\
\hline & $\begin{array}{l}\text { Empreendimentos Economia Solidárias que produzem sem } \\
\text { agrotóxicos }(2007)(+)\end{array}$ & $\begin{array}{l}\% \text { sobre total } \\
\text { estab. }\end{array}$ & $\begin{array}{l}\text { Ministério Trabalho } \\
\text { Emprego }\end{array}$ \\
\hline & Domicílios Rurais sem banheiro ou sanitário (2000) (-) & $\begin{array}{l}\% \text { sobre total } \\
\text { domicílios rurais }\end{array}$ & $\begin{array}{l}\text { Censo Demográfico - } \\
\text { IBGE }\end{array}$ \\
\hline & Domicílios Rurais destino esgoto: VALA (2000) (-) & $\begin{array}{l}\% \text { sobre total } \\
\text { domicílios rurais }\end{array}$ & $\begin{array}{l}\text { Censo Demográfico - } \\
\text { IBGE }\end{array}$ \\
\hline
\end{tabular}

Quadro 1. Dimensões, Indicadores e Unidades de Medida e Fonte dos dados

Fonte: Elaborado pelo autor a partir das bases de dados das fontes. 
Para fins de identificação da relação da variável com o processo de desenvolvimento, operacionalizou-se da seguinte forma:

- se a relação da variável com o desenvolvimento é positiva, então:

$$
I=\frac{x-m}{M-m}
$$

- se a relação da variável com o desenvolvimento é negativa, então:

$$
I=\frac{M-x}{M-m}
$$

sendo: I = índice calculado referente a cada variável, para cada microrregião investigada; $\boldsymbol{x}=$ valor observado de cada variável em cada microrregião investigada; $\boldsymbol{m}=$ valor mínimo considerado; $M=$ valor máximo considerado.

Há, portanto, uma relação positiva que resulta em melhoria do sistema como um todo quando o aumento no valor da variável resulta em melhora do sistema (+). Contrariamente, há uma relação negativa se um aumento no valor da variável resulta em piora do sistema (-). Esta prerrogativa nos auxilia na medida em que associa o (possível) crescimento da variável e seu (possível) impacto sobre o desenvolvimento.

A metodologia adotada é relativamente simples se comparada a outros estudos em que são aplicados modelos e técnicas estatísticas mais elaboradas. Mesmo assim acreditamos que apesar disso a mesma é robusta na medida em que o objetivo é identificar um cenário de possíveis mudanças nas dinâmicas regionais e em que medida a produção de tabaco participa e, mesmo que hipoteticamente, exerce alguma influência. Em tempos de plena cristalização da base exportadora primária do Rio Grande do Sul e da respectiva fragilização das economias regionais parece bastante oportuno trazer ao debate o quanto este cenário recente pode ter outros desdobramentos, tais como o fortalecimento dos fluxos migratórios e os impactos ambientais e para a saúde humana em função do uso abusivo e indiscriminado de agrotóxicos.

\section{As desiguais condições de manifestação do Desenvolvimento Rural no Rio Grande do Sul}

Antes de avançar na identificação das desiguais condições em que se manifesta o desenvolvimento rural no Rio Grande do Sul é importante registrar que não é possível fazer comparações temporais (com base em dois ou mais 
pontos no tempo) e tampouco estabelecer qualquer aproximação a práticas e/ou a processos evolutivos em termos de (in)sustentabilidade, pois demandaria comparar períodos no tempo e não apenas recortes territoriais tal como se procede neste trabalho. Trata-se, neste caso, de uma fotografia das condições em que se manifesta o desenvolvimento rural em escala microrregional embora reconheça-se que tais manifestações refletem as trajetórias regionais observadas.

$\mathrm{Na}$ sequência passa-se então à apresentação e à análise dos principais dados extraídos para composição do IDR e a suas desigualdades regionais. A variável que poderia aqui ser chamada independente, ao menos para fins heurísticos, é a área plantada com tabaco comparando o ano 2000 com o ano 2008. Refiro-me a fins heurísticos, pois a referida variável não tem peso na composição do IDR. Apenas nos é útil em função das motivações para realização deste trabalho, já detalhadas na introdução, bem como pelos resultados obtidos, facilitando acima de tudo a comparação.

Mais uma vez registra-se a impossibilidade de estabelecer qualquer tipo de relação causal entre aumento da área plantada com fumo e piora nos indicadores de desenvolvimento rural. Neste momento, a preocupação é testar a hipótese de que o avanço na área cultivada com tabaco se deu no período considerado fundamentalmente em regiões mais empobrecidas, de indicadores mais frágeis de desenvolvimento rural, e que essa realidade coincide com as regiões tradicionalmente produtoras de tabaco, bem como naquelas em que o tabaco é uma novidade. No limite, significa testar a hipótese de que a fumicultura está presente e avança nas regiões caracterizadas, senão pela pobreza rural, mas certamente pelo baixo dinamismo rural.

\subsection{As desigualdades regionais e o avanço recente da fumicultura}

Para facilitar a comparação entre as regiões (já que não é possível qualquer tipo de comparação temporal) definiu-se pela criação de uma tipologia (que na prática representa ranking do IDR) para representar as variações regionais dos IDR. Trata-se, eminentemente, de uma ferramenta para facilitar a análise e a compreensão das semelhanças e diferenças encontradas, neste caso representadas pelos subíndices e pelas dimensões de cada microrregião e, num segundo momento, sistematizados numa tipologia.

Respeitando a proposta metodológica, as microrregiões foram assim agregadas: microrregiões de IDR Extremamente Baixo (quando IDR era inferior a 0,449); microrregiões de IDR Baixo (quando IDR variava entre 0,450 a 0,499); microrregiões de IDR Médio (quando IDR variava entre 0,500 a 0,549); microrregiões de IDR Médio-Alto (quando IDR variava entre 0,550 a 0,599); e microrregiões de IDR Alto (quando IDR era superior a 0,600).

Antes de passar à análise comparativa dos dados, é importante registrar como se comportou a área plantada com tabaco entre 2000 e 2008, já considerando os níveis de desenvolvimento rural, que são melhor apresentados na Tabela 2. Já de antemão, destaca-se que o fumo, pelo menos no Rio Grande do 
Sul, concentra-se em regiões de desenvolvimento rural médio e baixo, com pouca variação percentual na comparação entre os anos considerados, o que não se confirma quando se toma por referência os valores absolutos, em hectares. Percebe-se que, embora a área plantada com tabaco tenha crescido em todas as regiões, os incrementos mais significativos, e que representam o perfil das novas áreas fumicultoras, foram observados nas regiões menos dinâmicas quanto ao desenvolvimento rural, com destaque para IDR Extremamente Baixo, onde incremento na área plantada foi superior a 74\%. Em seu conjunto, as regiões de IDR Extremamente Baixo, Baixo e Médio representam tanto em 2000 quanto em 2008, aproximadamente $86 \%$ da área plantada total com tabaco no Rio Grande do Sul.

Tabela 1. Área plantada com tabaco (ha) e variação (\%) (2000/2008) a partir dos níveis de desenvolvimento rural

\begin{tabular}{lccccc}
\hline $\begin{array}{l}\text { Níveis } \\
\text { Desenvolvimento } \\
\text { Rural }\end{array}$ & \multicolumn{2}{c}{2000} & \multicolumn{2}{c}{2008} & $\begin{array}{c}\text { Variação área } \\
\text { plantada fumo } \\
2000-2008\end{array}$ \\
\cline { 2 - 5 } Extremamente Baixo & 8.018 & 5,51 & 13.983 & 6,47 & 74,40 \\
Baixo & 40.759 & 28,02 & 59.897 & 27,70 & 46,95 \\
Médio & 76.462 & 52,56 & 112.821 & 52,18 & 47,55 \\
Médio-Alto & 7.095 & 4,88 & 11.304 & 5,23 & 59,32 \\
Alto & 13.146 & 9,04 & 18.191 & 8,41 & 38,38 \\
\hline Rio Grande do Sul & 145.480 & 100,00 & 216.196 & 100,00 & 48,61 \\
\hline
\end{tabular}

Fonte: FEEDADOS (2010)

Também cabe registrar o expressivo aumento na área cultivada com tabaco em termos estaduais, passando de 145 mil para 216 mil hectares num período de 8 anos. Ainda assim, é importante indicar que se o ano-base fosse 2006, seria possível observar redução na área cultivada com tabaco em praticamente todas as regiões. Essa redução na área plantada pode ser resultado de uma série de ações, tais como: migração voluntária ou orientada para outros cultivos; ações de diversificação produtiva motivadas pelo MDA em parceria com instituições públicas e da sociedade civil organizada; aquisição das áreas por terceiros para fins de moradia, entre outras. Tomemos tais questões como hipóteses, somente.

$\mathrm{Na}$ Tabela 2 a seguir é possível visualizar com mais propriedade o resultado da agregação dos 35 indicadores (Quadro 1) para cada uma das 35 microrregiões consideradas (Figura 1), já estabelecida a tipologia quanto ao IDR, bem como individualmente para cada uma das 5 dimensões e respectivo IDR médio resultante. Esse, por sua vez, resulta da média identificada das 5 dimensões. Por isso, o que assemelha ou diferencia as microrregiões não é a existência de áreas de cultivo de tabaco e sim os 35 indicadores selecionados.

A disposição das microrregiões é dada a partir do ordenamento crescente do IDR médio (que pode variar de 0 a 1), que tem como limite inferior a microrregião de Soledade (IDR 0,421) e limite superior a microrregião de Caxias do Sul (IDR 0,688). O IDR médio para o conjunto das microrregiões foi 0,531, equivalente ao encontrado para as microrregiões de Osório e Restinga Seca. 
Tabela 2. Índices de Desenvolvimento Rural (IDR), por níveis e dimensões para as microrregiões e agregado

\begin{tabular}{|c|c|c|c|c|c|c|c|}
\hline \multirow{2}{*}{$\begin{array}{c}\text { Níveis } \\
\text { Desenvolvimento } \\
\text { Rural } \\
\end{array}$} & \multirow{2}{*}{$\begin{array}{l}\text { Microrregiões } \\
\text { Representativas }\end{array}$} & \multicolumn{5}{|c|}{ Dimensões Representativas } & \multirow{2}{*}{$\begin{array}{c}\text { Índice de } \\
\text { Desenvolvimento } \\
\text { Rural (médio) }\end{array}$} \\
\hline & & Social & $\begin{array}{l}\text { Demográ- } \\
\text { fica }\end{array}$ & $\begin{array}{c}\text { Político- } \\
\text { Institucional }\end{array}$ & $\begin{array}{l}\text { Econômi- } \\
\text { ca }\end{array}$ & Ambiental & \\
\hline \multirow{3}{*}{$\begin{array}{l}\text { IDR Extremamente } \\
\text { Baixo }(0,420 \text { a } \\
0,449)\end{array}$} & Soledade & 0,377 & 0,586 & 0,337 & 0,401 & 0,402 & 0,421 \\
\hline & Serras do Sudeste & 0,436 & 0,581 & 0,262 & 0,400 & 0,445 & 0,425 \\
\hline & Campanha Central & 0,424 & 0,637 & 0,273 & 0,496 & 0,407 & 0,447 \\
\hline \multirow{9}{*}{$\begin{array}{l}\text { IDR Baixo }(0,450 \text { a } \\
0,499)\end{array}$} & Jaguarão & 0,466 & 0,580 & 0,299 & 0,570 & 0,370 & 0,457 \\
\hline & Camaquã & 0,470 & 0,606 & 0,429 & 0,460 & 0,356 & 0,464 \\
\hline & São Jerônimo & 0,519 & 0,654 & 0,243 & 0,555 & 0,380 & 0,470 \\
\hline & $\begin{array}{l}\text { Frederico } \\
\text { Westphalen }\end{array}$ & 0,494 & 0,609 & 0,385 & 0,419 & 0,494 & 0,480 \\
\hline & Santiago & 0,486 & 0,618 & 0,344 & 0,458 & 0,525 & 0,486 \\
\hline & Vacaria & 0,510 & 0,628 & 0,373 & 0,536 & 0,386 & 0,487 \\
\hline & Cachoeira do Sul & 0,501 & 0,654 & 0,363 & 0,456 & 0,480 & 0,491 \\
\hline & Santo Ângelo & 0,599 & 0,623 & 0,337 & 0,409 & 0,508 & 0,495 \\
\hline & Cerro Largo & 0,613 & 0,614 & 0,348 & 0,416 & 0,502 & 0,499 \\
\hline \multirow{12}{*}{$\begin{array}{l}\text { IDR Médio (0,500 a } \\
0.549)\end{array}$} & Litoral Lagunar & 0,482 & 0,643 & 0,418 & 0,501 & 0,456 & 0,500 \\
\hline & $\begin{array}{l}\text { Campanha } \\
\text { Meridional }\end{array}$ & 0,668 & 0,574 & 0,350 & 0,538 & 0,386 & 0,503 \\
\hline & Três Passos & 0,525 & 0,642 & 0,436 & 0,421 & 0,494 & 0,504 \\
\hline & Pelotas & 0,535 & 0,692 & 0,460 & 0,438 & 0,400 & 0,505 \\
\hline & Sananduva & 0,516 & 0,616 & 0,445 & 0,477 & 0,501 & 0,511 \\
\hline & $\begin{array}{l}\text { Campanha } \\
\text { Ocidental }\end{array}$ & 0,513 & 0,606 & 0,404 & 0,622 & 0,423 & 0,514 \\
\hline & Carazinho & 0,516 & 0,677 & 0,427 & 0,464 & 0,557 & 0,528 \\
\hline & Osório & 0,561 & 0,696 & 0,487 & 0,459 & 0,441 & 0,529 \\
\hline & Restinga Seca & 0,588 & 0,618 & 0,451 & 0,473 & 0,538 & 0,534 \\
\hline & Santa Maria & 0,554 & 0,712 & 0,542 & 0,443 & 0,464 & 0,543 \\
\hline & Erechim & 0,559 & 0,676 & 0,438 & 0,507 & 0,548 & 0,546 \\
\hline & Santa Cruz do Sul & 0,580 & 0,699 & 0,473 & 0,464 & 0,517 & 0,547 \\
\hline \multirow{4}{*}{$\begin{array}{l}\text { IDR Médio-Alto } \\
(0,550 \text { a }(0.599)\end{array}$} & Santa Rosa & 0,650 & 0,710 & 0,439 & 0,464 & 0,553 & 0,563 \\
\hline & ljuí & 0,575 & 0,690 & 0,515 & 0,473 & 0,579 & 0,566 \\
\hline & Cruz Alta & 0,541 & 0,667 & 0,603 & 0,514 & 0,557 & 0,577 \\
\hline & Guaporé & 0,686 & 0,671 & 0,523 & 0,602 & 0,491 & 0,595 \\
\hline \multirow{7}{*}{$\begin{array}{l}\text { IDR Alto (acima de } \\
0,600 \text { ) }\end{array}$} & Passo Fundo & 0,594 & 0,710 & 0,630 & 0,568 & 0,500 & 0,600 \\
\hline & Lajeado - Estrela & 0,639 & 0,783 & 0,528 & 0,539 & 0,515 & 0,601 \\
\hline & Gramado-Canela & 0,681 & 0,825 & 0,520 & 0,511 & 0,558 & 0,619 \\
\hline & Não-me-Toque & 0,632 & 0,715 & 0,541 & 0,574 & 0,645 & 0,622 \\
\hline & Montenegro & 0,718 & 0,799 & 0,467 & 0,566 & 0,561 & 0,622 \\
\hline & Porto Alegre & 0,718 & 0,778 & 0,626 & 0,575 & 0,460 & 0,631 \\
\hline & Caxias do Sul & 0,795 & 0,842 & 0,708 & 0,627 & 0,470 & 0,688 \\
\hline
\end{tabular}

Fonte: Organizado pelo autor a partir dos dados 
Com base nesses dados é possível estabelecer algumas considerações importantes: (1) de uma forma em geral as regiões fumicultoras apresentam indicadores de desenvolvimento rural mais acanhados; (2) a fumicultura avançou de forma ainda mais expressiva nas regiões que apresentam dinâmicas de desenvolvimento rural ainda mais exíguas; (3) há uma ampla variação nos IDR, demonstrando que o desenvolvimento rural no Rio Grande do Sul assume ampla heterogeneidade empírica; (4) esta mesma variação (amplitude) é observada quando se compara as dimensões ou instâncias consideradas; e (5) a variação nas instância ou dimensões indica variações importantes no interior das próprias microrregiões e nos seus agregados. Nesse sentido, observa-se desarmonia tanto entre as dinâmicas regionais de desenvolvimento rural quanto internamente a elas.

Além da apresentação do IDR (Tabela 2) é fundamental qualificar a diferenciação regional com base em alguns indicadores, apontando parâmetros qualitativos dos padrões encontrados. O que de fato diferencia as dinâmicas regionais de desenvolvimento rural? Quais seus perfis? Quais os parâmetros empíricos do que Marsden (2003) denominou de dinâmicas territoriais e desiguais de desenvolvimento do capitalismo no espaço agrário ${ }^{5}$ ?

De qualquer forma, cabe resgatar e reafirmar a proposição de Veiga (2000) de que regiões que possuem uma agricultura familiar consolidada, combinada a um processo de urbanização e industrialização endógeno, descentralizado e promissor acabam conseguindo estabelecer um processo de desenvolvimento mais equilibrado, com geração de emprego em várias atividades, absorvendo tanto excedentes de mão de obra da área local rural, quanto de outras regiões. A produção tanto agrícola quanto industrial é diversificada, gerando um grande volume de produtos exportáveis, e com uso razoavelmente adequado dos recursos locais.

Trabalhos já produzidos, e aqui referenciados, indicam que regiões fumicultoras apresentam indicadores de desenvolvimento abaixo da média, quando comparados com agregados estaduais e na comparação com as demais regiões. Os dados apresentados neste trabalho permitem considerar que as regiões fumicultoras são menos dinâmicas também em relação ao desenvolvimento rural. Pequena síntese dessa realidade é apresentada na Tabela 3. Embora alguns indicadores, como é o caso do número de pessoas ocupadas por estabelecimento agropecuário não apresentar diferenças significativas (mínimo de 3,02 a máximo de 3,29), outros são bem mais díspares.

\footnotetext{
${ }^{5}$ Os limites de configuração deste trabalho nos impedem de avançar neste debate pois nos levaria, inevitavelmente, a tipificar os 5 padrões encontrados buscando a unicidade interna e a diferenciação territorial. Esta etapa será feita em outro momento.
} 
Tabela 3. Indicadores das dinâmicas desiguais de desenvolvimento do espaço agrário gaúcho

\begin{tabular}{|c|c|c|c|c|c|c|c|c|}
\hline $\begin{array}{c}\text { Níveis } \\
\text { Desenvolvimento } \\
\text { Rural }\end{array}$ & $\begin{array}{l}\text { Tx Anal. } \\
\text { Rural (\%) }\end{array}$ & $\begin{array}{c}\text { Pes. entre } 18 \text { e } \\
29 \text { anos freq. } \\
\text { curso superior } \\
(\%)\end{array}$ & $\begin{array}{c}\text { Domicílios } \\
\text { rurais linha } \\
\text { telefônica } \\
\text { instalada (\%) } \\
\end{array}$ & $\begin{array}{l}\text { Tx Urb. } \\
(\%)\end{array}$ & $\begin{array}{l}\text { Pessoa } \\
\text { ocupada } \\
\text { estab. } \\
\text { Agrop. }\end{array}$ & $\begin{array}{c}\text { Domicílios } \\
\text { rurais com } \\
\text { automóvel } \\
(\%)\end{array}$ & $\begin{array}{l}\text { Partic. } \\
\text { AGROP/ } \\
\text { VAB }\end{array}$ & $\begin{array}{l}\text { Partic. } \\
\text { IND/ } \\
\text { VAB }\end{array}$ \\
\hline $\begin{array}{l}\text { IDR Extremamente } \\
\text { Baixo }\end{array}$ & 16,69 & 6,43 & 4,05 & 64,00 & 3,02 & 31,84 & 24,64 & 16,86 \\
\hline IDR Baixo & 11,99 & 9,04 & 8,03 & 66,92 & 3,29 & 35,60 & 26,62 & 19,51 \\
\hline IDR Médio & 11,28 & 10,03 & 9,13 & 70,38 & 3,28 & 38,36 & 18,49 & 21,83 \\
\hline IDR Médio-Alto & 7,91 & 11,79 & 18,77 & 67,43 & 3,21 & 51,37 & 20,09 & 21,46 \\
\hline IDR Alto & 6,98 & 12,85 & 26,44 & 79,14 & 3,10 & 54,16 & 10,29 & 31,84 \\
\hline
\end{tabular}

Fonte: Organizado pelo autor a partir dos dados

Exemplo desta disparidade regional é a taxa de analfabetismo rural, que chega a quase $17 \%$ nas microrregiões de IDR Extremamente Baixo, percentual 3 vezes superior ao encontrado nas microrregiões de IDR Médio-Alto e IDR Alto. Importantes também são as diferenças no percentual de pessoas entre 18 e 29 anos que, em 2000, frequentavam ensino superior, porém numa relação inversa. $\mathrm{O}$ acesso a determinados bens e serviços também é diferenciado. Basta observar o acesso a linha telefônica e a automóvel. Nesse sentido, merece destaque o baixo percentual de domicílios rurais com acesso a linha telefônica nas regiões de IDR Extremamente Baixo, Baixo e Médio, 4,05\%, 8,03\% e 9,13\% respectivamente. Já entre as regiões de IDR Médio-Alto e IDR Alto os percentuais são significativamente superiores, o que também ocorre quando se analisa $O$ percentual de domicílios rurais com automóvel.

A taxa de urbanização também apresenta variações consideráveis. A título de exemplo pode-se citar que nas microrregiões que compõem o IDR Extremamente Baixo, a taxa de urbanização é de $48,6 \%$ na microrregião de Soledade; de 53,\% na Serras do Sudeste; e de $89,6 \%$ na Campanha Central. Tomando-se apenas as duas primeiras microrregiões, onde o avanço da fumicultura no período considerado foi elevado, a taxa média de urbanização seria de $51,2 \%$ e não de $64 \%$. Disso pode-se inferir que as regiões de menor desenvolvimento rural poderiam ser reconhecidas como tipicamente rurais, quando se toma a taxa de urbanização como parâmetro. De qualquer forma, isso vai ao encontro das perspectivas de Veiga (2002), Abramovay (2003) a respeito da importância das cidades médias na emulação do desenvolvimento rural, na medida em que a proximidade geográfica, quando associada a níveis satisfatórios de renda e de diversificação das economias locais, amplia o portfólio de opções de inserção no mercado de trabalho não agrícola para população rural e mesmo a oferta de produtos (da cesta de alimentos) e de serviços (turismo rural) para a população urbana.

As regiões que apresentam os menores níveis de IDR, como é o caso dos níveis Extremamente Baixo e Baixo, são regiões onde o peso da agropecuária na formaçãao do Valor Agregado Bruto (VAB) é maior do que nas regiões de IDR mais elevado. As regiões de IDR mais elevado são as que apresentam perfil mais industrial do que agropecuário, o que reforça a importância da proximidade e da 
integração intersetorial da agricultura, seja pela via dos produtos e serviços seja pela via do mercado de trabalho não agrícola, dado que desenvolvimento rural não se faz apenas com oferta de crédito, terra, tecnologias ou fomento à produtividade.

Outra forma de analisar as desiguais manifestações do desenvolvimento rural é reconhecer as assimetrias entre as dimensões de uma mesma região. Os dados da Tabela 4 permitem considerar que quanto menor o IDR médio do agregado regional, maior é a assimetria interna do IDR. Nesse sentido, a diferença entre o menor e o maior IDR de um mesmo nível diminui na medida em que melhora o IDR médio. A título de exemplo pode-se citar que enquanto a diferença entre o menor $(0,299)$ e o maior $(0,584)$ IDR (respectivamente representados pelas dimensões político-institucional e demográfica) nas microrregiões de IDR Extremamente Baixo é superior a 95\%, nas microrregiões de IDR Alto, o maior IDR $(0,779)$ representado pela dimensão demográfica é $46,7 \%$ superior ao menor IDR $(0,530)$, representado pela dimensão ambiental.

Tabela 4. Subíndices e IDR médios, por dimensão e níveis

\begin{tabular}{|c|c|c|c|c|c|c|}
\hline \multirow{2}{*}{$\begin{array}{l}\text { Níveis Desenvolvimento } \\
\text { Rural }\end{array}$} & \multicolumn{5}{|c|}{ Dimensões Representativas } & \multirow{2}{*}{$\begin{array}{l}\text { IDR } \\
\text { médio }\end{array}$} \\
\hline & Social & Demográfica & Político-Instit. & Econômica & Ambiental & \\
\hline Extremamente Baixo & 0,407 & 0,584 & 0,299 & 0,400 & 0,423 & 0,431 \\
\hline Baixo & 0,508 & 0,622 & 0,339 & 0,478 & 0,441 & 0,481 \\
\hline Médio & 0,550 & 0,654 & 0,444 & 0,484 & 0,477 & 0,522 \\
\hline Médio-Alto & 0,613 & 0,684 & 0,520 & 0,513 & 0,545 & 0,575 \\
\hline Alto & 0,682 & 0,779 & 0,574 & 0,566 & 0,530 & 0,626 \\
\hline
\end{tabular}

Fonte: FEEDADOS (2010)

O fundamental a reter da Tabela 4 é que as regiões de IDR maior apresentam maior harmonia ou menos assimetria entre as instâncias ou dimensões. Contrariamente, as regiões de IDR mais baixos são regiões que se caracterizam por um desenvolvimento rural mais desarmônico ou desigual. Tanto a relativa harmonia quanto a desarmonia podem ser observadas no Gráfico 1 e nos Gráficos 2, 3, 4, 5 e 6. Estes, por sua vez, representam cada um dos níveis de IDR encontrados para agregado específico de regiões, por dimensão. Fica evidente que os Gráficos 1, 2 e 3, além de ocuparem áreas menores, pois apresentam IDR médios mais baixos, expõem claramente uma desarmonia entre as dimensões. Essa desarmonia é atenuada ou quase imperceptível nos níveis Médio-Alto e Alto, respectivamente Gráficos 5 e 6. 


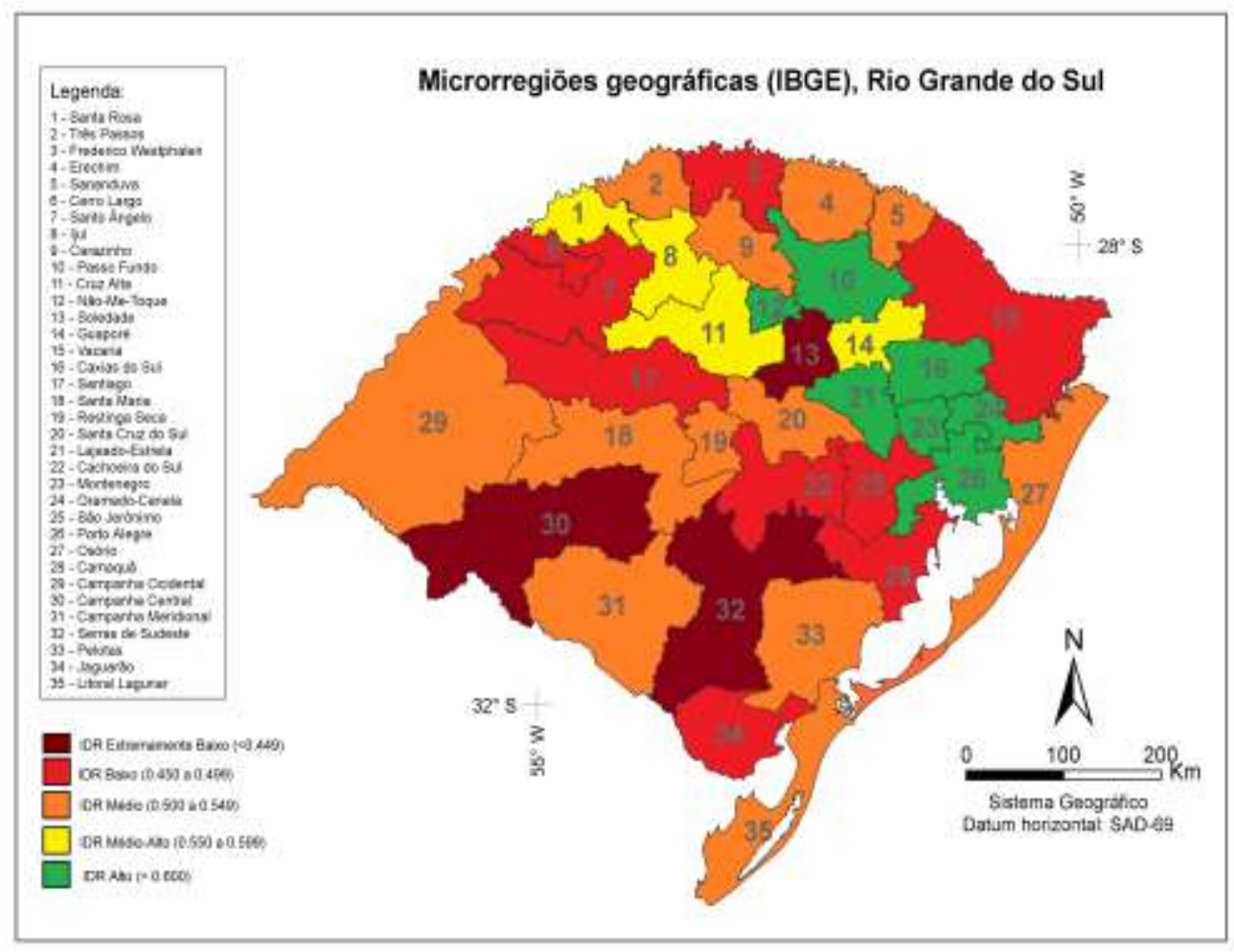

Figura 2. Índices de Desenvolvimento Rural (IDR) microrregiões do Rio Grande do Sul

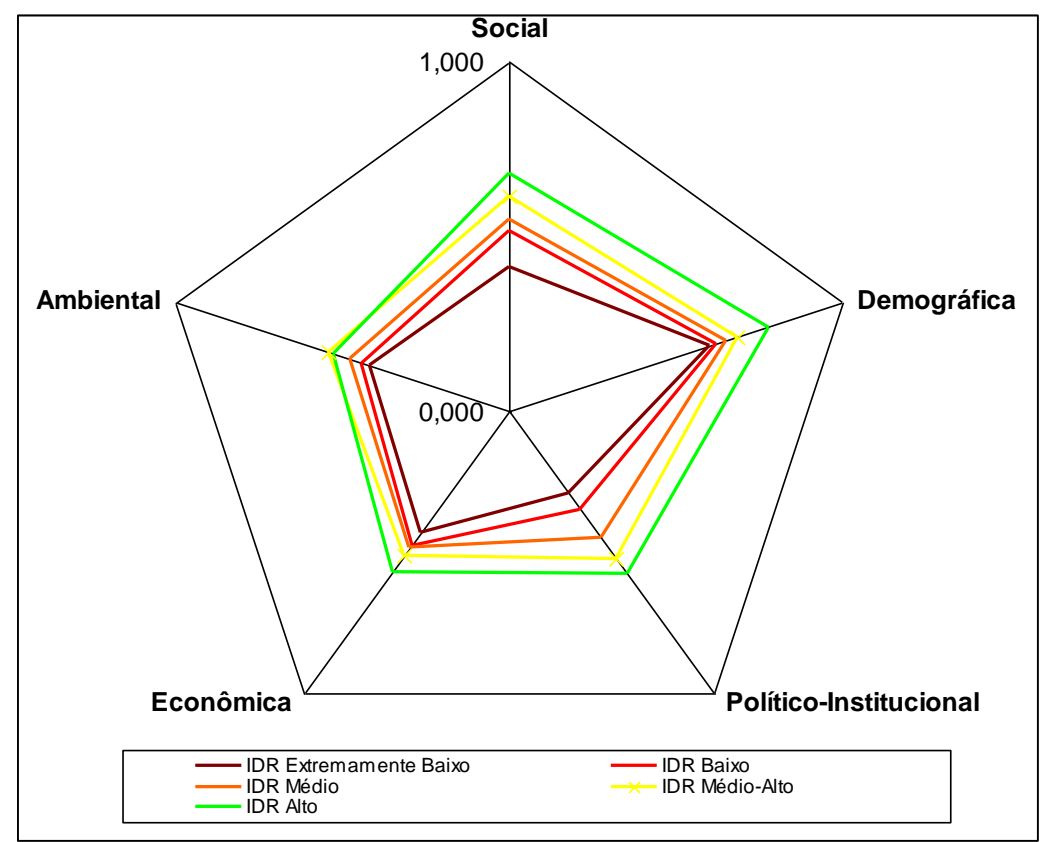

Gráfico 1. Índices de Desenvolvimento Rural (IDR), por dimensão Fonte: Organizado pelo autor a partir dos dados 
A Figura 2 é representativa das desiguais condições em que se manifesta 0 desenvolvimento rural no Rio Grande do Sul. Os Gráficos 2, 3, 4, 5 e 6 expressam a intensidade e o formato das desiguais condições em que se manifesta o desenvolvimento rural no Rio Grande do Sul, permitindo reconhecer o seu formato a partir das dimensões e sua intensidade a partir dos índices.

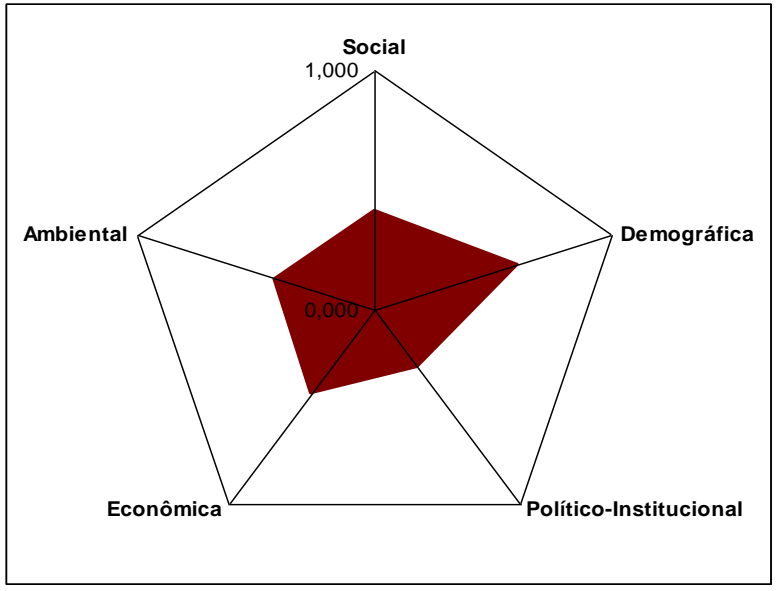

Gráfico 2. Biograma IDR Extremamente Baixo. por dimensão

Fonte: Organizado pelo autor

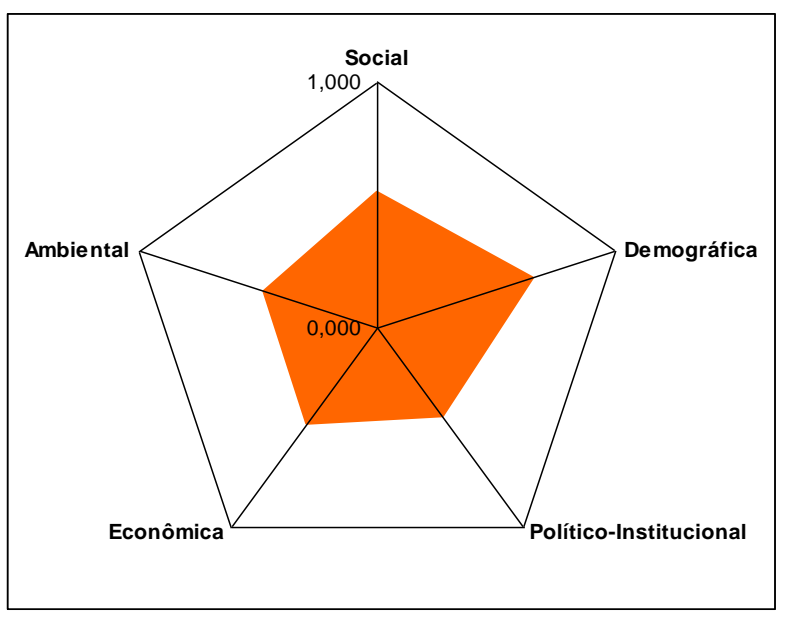

Gráfico 4: Biograma IDR Médio, por dimensão

Fonte: Organizado pelo autor

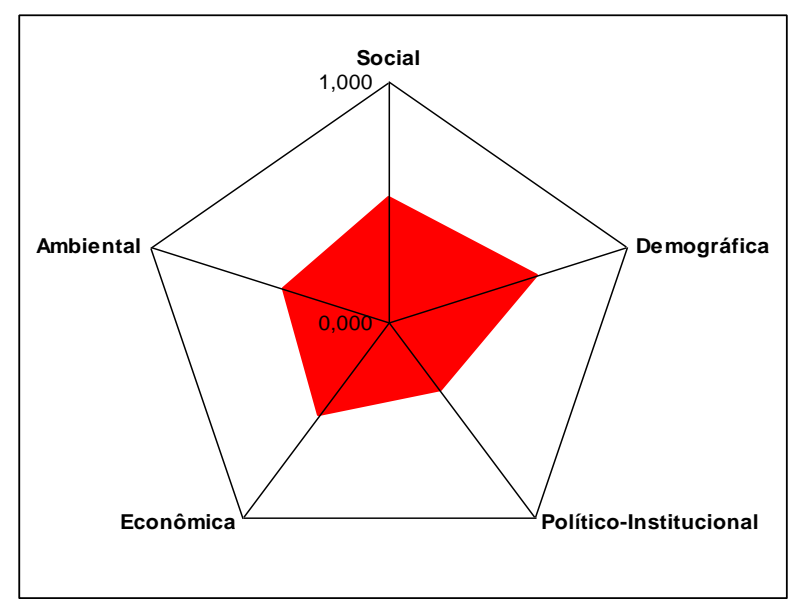

Gráfico 3. Biograma IDR Baixo, por dimensão

Fonte: Organizado pelo autor

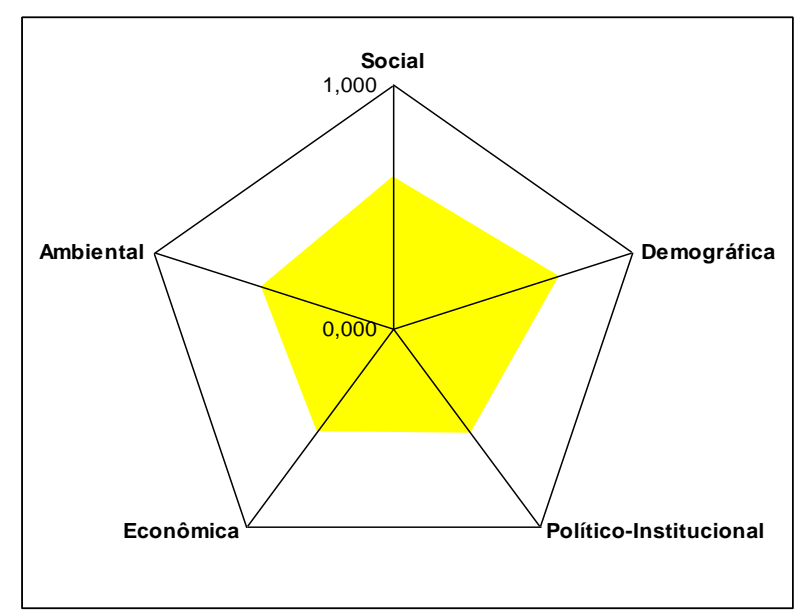

Gráfico 5: Biograma IDR Médio-Alto, por dimensão

Fonte: Organizado pelo autor 


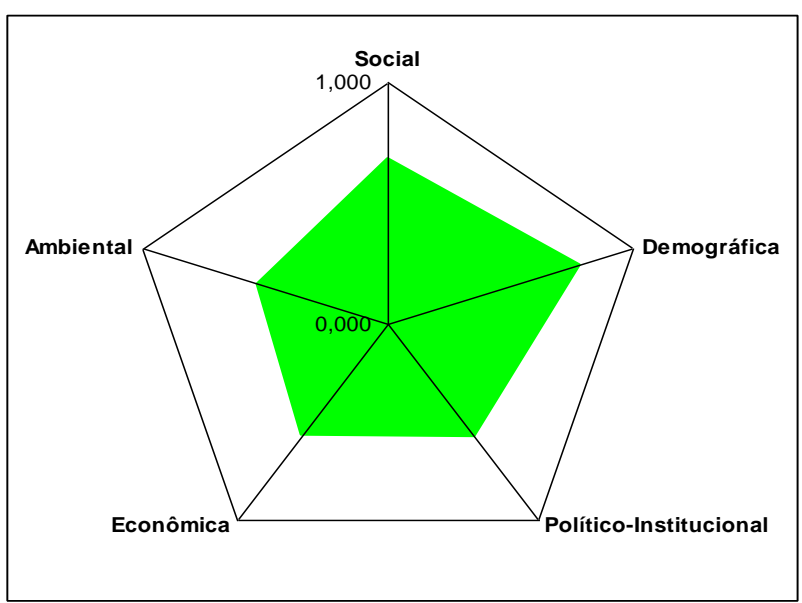

Gráfico 6. Biograma IDR Alto, por dimensão

Fonte: Organizado pelo autor

Além das observações apresentadas, o conjunto de dados, figuras e gráficos permitem considerar que tanto maior é o desenvolvimento rural, quanto mais próximo do rural estiver um centro ou pólo econômico importante, fundamentalmente centros urbanos médio, demonstrando que a proximidade com mercados consumidores e de trabalho não-agrícola importantes pode exercer papel fundamental para o desenvolvimento dos espaços rurais.

\section{Considerações finais}

Inicialmente havíamos definido que um dos objetivos deste trabalho era o de estabelecer possíveis associações entre o avanço da fumicultura com as dinâmicas de desenvolvimento rural existentes. Buscava-se subsídios que pudessem respaldar a hipótese de que o fumo avançava fundamentalmente nas regiões de desenvolvimento rural menos dinâmico e de agricultura familiar mais frágil. A impossibilidade de estabelecer associações causais entre aumento da fumicultura e condições de desenvolvimento nos impôs a necessidade de reconstruir a metodologia para que os resultados não fossem distorcidos e a hipótese pudesse ser efetivamente testada. Surgiu, assim, a necessidade de, num primeiro momento, caracterizar multidimensionalmente o desenvolvimento rural para as microrregiões do Rio Grande do Sul e, a partir disso, reconhecer se o avanço da fumicultura se dava em regiões de menor ou maior IDR.

Os resultados obtidos permitem importantes considerações a respeito das desiguais condições em que o desenvolvimento rural encontra respaldo empírico no Rio Grande do Sul. Não obstante, vale ressaltar que se trata de um estudo de caráter exploratório e não conclusivo e que futuras pesquisas terão espaço. Isso nos permite inferir que o avanço da fumicultura no Rio Grande do Sul se dá em função de um conjunto de aspectos, sem esquecer é claro outros não tratados aqui (aumento da demanda mundial, rigor nas restrições sociais e ambientais em nações mais desenvolvidas, etc.): a persistência histórica de amplas desigualdades 
regionais de desenvolvimento consolidadas ao longo do tempo pela permanência de um modelo agrícola de desenvolvimento rural (economias de escala, produtividade e eficiência técnica); a presença maciça de agricultores familiares com mínimo de área e mão de obra disponíveis para assumir novos formatos técnico-produtivos; o apoio/acompanhamento técnico disponibilizado pelas empresas integradoras, muitas vezes reflexo da não oferta de serviços públicos de assistência técnica e extensão rural; e pela dificuldade do agricultor familiar em fazer escolhas em função de certa condição/situação de vulnerabilidade social, indicando ser a fumicultura mais uma condição de imposição do que necessariamente uma escolha deliberada.

Tomando-se as microrregiões como recorte territorial, as variáveis descritas no Quadro 1 como indicadores de desenvolvimento, a análise multidimensional enquanto proposta metodológica e o IDR como parâmetro comparativo pode-se estabelecer as seguintes considerações em relação a este trabalho: (1) não há um padrão único de desenvolvimento rural no Rio Grande do Sul - o desenvolvimento rural no RS é marcado pela diversidade de dinâmicas; (2) mesmo entre as regionalizações já consolidadas pela literatura (Sul, Norte e Nordeste) observa-se variedade importante dos níveis de desenvolvimento rural pois não há um Norte gaúcho homogêneo, como também não há um Sul homogêneo, embora seja possível falar em um Noroeste homogêneo; (3) por conta disso, fica cada vez mais difícil falar em grandes padrões de desenvolvimento rural mesmo no Rio Grande do Sul; (4) o Norte do Rio Grande do Sul é a região mais representativa da geografia econômica gaúcha, pois nesta porção do estado é possível encontrar todos os níveis de desenvolvimento rural, do Extremamente Baixo ao IDR; e (5) das 3 microrregiões de pior IDR, duas se encontram na porção Sul e uma na porção Norte.

Apesar de se tratar de uma ferramenta metodológica importante e de fácil manuseio, há pelo menos um limite importante em relação a este trabalho. Isso porque não é possível estabelecer relações causais entre o avanço da área plantada com tabaco e as expressões empíricas do desenvolvimento rural. Da mesma forma, por se tratar de dados em um ponto no tempo, não se pode falar em termos de sustentabilidade. Essas limitações serão sanadas em estudo futuro. A partir disso espera-se ter em mãos uma proposta metodológica que permita estabelecer um diálogo com aquilo que Kageyama (2008) definiu como os fatores condicionantes do desenvolvimento rural, as diferenças nas trajetórias que determinaram as características do desenvolvimento rural e os resultados econômicos e sociais para as populações envolvidas, dentre os quais incluem-se a redução do êxodo rural, a elevação da renda e a redução da pobreza, a melhoria das condições de vida e da escolaridade. Isso permitiria avançar significativamente em termos analíticos das expressões da ruralidade contemporânea.

Nesse caso, seria possível também avançar no debate acerca de que a fumicultura se apresenta aos agricultores familiares como uma estratégia de reação (na perspectiva de ELLIS, 2000), ou seja, uma ação imediata que indicaria a impossibilidade de fazer escolhas (SEN, 2000) em função da vulnerabilidade em que vivem esses agricultores. Em termos práticos, isso indicaria a existência de dinâmicas de desenvolvimento rural e territorial exógenas e economias de escala e 
especialização, fatores que na perspectiva de Veiga (2002), Abramovay (2003), Ploeg et al. (2000) e Ploeg (2008) limitam o fortalecimento das economias locais e as possibilidades de diversificação econômica, com implicações na forma com que a agricultura familiar interage com as políticas públicas e as dinâmicas locais (TONNEAU, SABOURIN, 2007).

Este trabalho, mesmo representando "fotografia" do estado de um sistema num ponto no tempo, oferece subsídios importantes para (re)pensar o formato da intervenção de ações públicas, pois indica quais de suas dimensões está mais carente e representa um limite importante na emulação do desenvolvimento rural.

\section{REFERÊNCIAS}

ABRAMOVAY, R. O futuro das regiões rurais. Porto Alegre: Editora da UFRGS, 2003.

BUAINAIN, A. M.; ALVES, E.; SILVEIRA, J. M. DA.; NAVARRO, Z. (Orgs.). O mundo rural no Brasil no século 21: a formação de um novo padrão agrícola e agrário. Brasília, DF: Embrapa, 2014.

BONATO, A. A. A fumicultura e a Convenção-Quadro - Desafios para a Diversificação. Departamento de Estudos Socioeconômicos Rurais (DESER) - Conjuntura. Curitiba, 2009.

CONTERATO, M. A. Dinâmicas regionais do desenvolvimento rural e estilos de agricultura familiar: uma análise a partir do Rio Grande do Sul. Tese (Desenvolvimento Rural), Universidade Federal do Rio Grande do Sul, Faculdade de Ciências Econômicas, Programa de Pós-Graduação em Desenvolvimento Rural. Porto Alegre, 2008.

CONTERATO, et al. Desenvolvimento rural no Estado do Rio Grande do Sul: uma análise multidimensional de suas desigualdades regionais. Redes Revista do Desenvo/vimento Regional, Santa Cruz do Sul, v. 12, n. 2, p. 163 -195 mai./ago. 2007.

CONTERATO, RADOMSKY E SCHNEIDER (Orgs.). Pesquisa em Desenvolvimento Rural: aportes teóricos e proposições metodológicas (Volume 1). Porto Alegre: Editora da UFRGS, 2014.

ELLIS, F. Rural livelihoods and diversity in developing countries. Oxford: Oxford University, 2000.

FEEDADOS. Banco de Dados da Fundação de Economia e Estatística (FEE). Porto Alegre, Secretaria de Planejamento do Estado do Rio Grande do Sul. 2010.

http://www.fee.rs.gov.br/feedados. Acesso em março de 2010.

KAGEYAMA, A. Desenvolvimento Rural Conceitos e Aplicação ao caso Brasileiro. Porto Alegre: Editora da UFRGS, 2008.

Desenvolvimento Rural no Rio Grande do Sul. In: SCHNEIDER, S. (org.). $A$ Diversidade da Agricultura Familiar. Porto Alegre: Editora da UFRGS, 2006.

MARSDEN, T. The condition of rural sustainability. Assen: Royal van Gorcum, 2003. 
MOLLARD, A. Multifonctionnalité de l'agriculture et territoires: dês concepts auxs politiques publiques. Cahiers d'économic et sociologie rurales, n. 66, p.28-54, 2003.

OCDE (Organisation for Econimc Co-Operation and Development). Territorial indicators of development- Focusing on rural development. Paris, 1996.

PLOEG, J. D. van der.; et al. Rural Development: from practices and policies towards theory. Sociologia Ruralis, Oxford, v. 40, n. 4, p. 391-407, 2000.

PLOEG, J. D. van der. Camponeses e Impérios Alimentares - Lutas por autonomia e sustentabilidade na era da globalização. Porto Alegre: Editora da UFRGS, 2008.

PERONDI, M. A. Diversificação dos meios de vida e mercantilização da agricultura familiar. 2007. Tese (Desenvolvimento Rural) - Faculdade de Ciências Econômicas, Universidade Federal do Rio Grande do Sul, Porto Alegre, 2007.

SCHNEIDER, S. (org.). A Diversidade da Agricultura Familiar. Porto Alegre: Editora da UFRGS, 2006.

SEN, A. Desenvolvimento como Liberdade. São Paulo: Companhia das Letras, 2000.

SEPÚLVEDA, S. Desenvolvimento microrregional sustentável: métodos para planejamento local. Brasília: Instituo Inter-Americano de Cooperação Agrícola, 2005.

TONNEAU, J. P; SABOURIN, E. (orgs). Agricultura familiar. interação entre políticas públicas e dinâmicas locais: ensinamentos a partir de casos. Porto Alegre: Editora da UFRGS, 2007.

VEIGA, J. E. Do crescimento agrícola ao desenvolvimento rural. In: CASTRO, A.C. Desenvolvimento em debate. Rio de Janeiro, Ed. Mauad/BNDES, 2002.

WAQUIL, P. D.; et al. Para medir o desenvolvimento territorial rural: validação de uma proposta metodológica. XLV Congresso da SOBER. Londrina, 2007.

Submetido em 23/12/2011

Aprovado em 02/04/2014

\section{Sobre os autores}

\section{Marcelo Antonio Conterato}

Mestre e Doutor em Desenvolvimento Rural. Professor no Departamento de Economia e Relações Internacionais (DERI) e no Programa de Pós-Graduação em Desenvolvimento Rural (PGDR) da Universidade Federal do Rio Grande do Sul (UFRGS).

Endereço: Avenida João Pessoa, 31. Centro. CEP 90040-000 - Porto Alegre - RS - Brasil.

E-mail: marcelo.conterato@ufrgs.br. 